\title{
A Quantitative Determination of Minimum Film Thickness in Elastohydrodynamic Circular Contacts
}

\section{Wassim Habchi}

Lebanese American University

Philippe Vergne ( $\nabla$ philippe.vergne@insa-lyon.fr)

LaMCoS, Laboratoire de Mecanique des Contacts et des Structures https://orcid.org/0000-0001-80586256

\section{Research Article}

Keywords: Minimum film thickness, Elastohydrodynamic lubrication (EHL), Circular contacts, Central to minimal film thickness ratio

Posted Date: May 24th, 2021

DOl: https://doi.org/10.21203/rs.3.rs-481507/v1

License: (9) This work is licensed under a Creative Commons Attribution 4.0 International License. Read Full License

Version of Record: A version of this preprint was published at Tribology Letters on September 26th, 2021. See the published version at https://doi.org/10.1007/s11249-021-01512-z. 


\title{
A Quantitative Determination of Minimum Film Thickness in Elastohydrodynamic Circular Contacts
}

\author{
Wassim Habchi ${ }^{1}$, Philippe Vergne ${ }^{*}$ \\ 1 Department of Industrial and Mechanical Engineering, Lebanese American University, Byblos, Lebanon \\ 2 Univ Lyon, CNRS, INSA Lyon, LaMCoS, UMR5259, 69621 Villeurbanne, France
}

\begin{abstract}
The current work presents a quantitative approach for the prediction of minimum film thickness in elastohydrodynamic lubricated (EHL) circular contacts. In contrast to central film thickness, minimum film thickness can be hard to accurately measure, and it is usually poorly estimated by classical analytical film thickness formulae. For this, an advanced finite-element-based numerical model is used to quantify variations of the central-to-minimum film thickness ratio with operating conditions, under isothermal Newtonian pure-rolling conditions. An ensuing analytical expression is then derived and compared to classical film thickness formulae and to more recent similar expressions. The comparisons confirmed the inability of the former to predict the minimum film thickness, and the limitations of the latter, which tend to overestimate the ratio of central-to-minimum film thickness. The proposed approach is validated against numerical results as well as experimental data from the literature, revealing an excellent agreement with both. This framework can be used to predict minimum film thickness in circular elastohydrodynamic contacts from knowledge of central film thickness, which can be either accurately measured or rather well estimated using classical film thickness formulae.
\end{abstract}

\section{Keywords}

Minimum film thickness; Elastohydrodynamic lubrication (EHL), Circular contacts; Central to minimal film thickness ratio

\section{Introduction and background}

Minimum film thickness in circular elastohydrodynamic (EHD) contacts has been significantly less studied than central film thickness and the mechanisms behind the former certainly less understood.

${ }^{*}$ Corresponding author: philippe.vergne@insa-lyon.fr 
Experimentally, rational explanations can be found for this contrasting situation. The first techniques developed to measure film thickness in elastohydrodynamic lubrication or EHL (voltage discharge, electrical resistance, capacitance, X-rays, see [1] for more detail), have mostly allowed a global or mean measurement of the gap between moving solids, i.e. determined over the whole contact area, finally considered as representative of the film thickness at its center.

It was not until the emergence of methods based on optical interferometry that it became possible to more accurately quantify the minimum film thickness, which has evolved towards a more quantitative concept with the availability of more sensitive CCD sensors with better spatial resolution. This last point is important because, unlike central film thickness which is representative of a relatively large surface, the minimum thickness area, which occurs on the so-called side lobes, is very small, sometimes reduced to a few $\mu \mathrm{m}^{2}$. This can make both its location and measurement uncertain or subject to approximations. This situation can take place in the case of highly loaded contacts or in the very thin film (VTF) regime, when the thickness of the lubricating film reaches molecular dimensions [2-5]. In addition, it is becoming more and more frequent, due to the need for reducing the environmental impact of systems (e.g., less viscous lubricants leading to lower friction losses, but also to an overall reduction in film thickness) and due to the increasing severity of operating conditions (e.g., higher loads, increased working temperatures). Although interferometric techniques have been widely used for at least two decades now, it is clear that measurements reported in the literature are overwhelmingly concerned with film thicknesses at the contact center and often ignore the minimum film thickness.

In terms of prediction, analytical expressions have been available for more than 4 decades now. They are based upon several operating parameters, usually bundled in dimensionless groups. They aim at predicting central and minimum film thicknesses in circular EHD contacts; sometimes in elliptical contacts as well. Surprisingly, it is not possible to confirm that all these expressions predict identical or very close values.

There is, however, relatively little work that has allowed an objective assessment of these EHD formulas. At most, one can cite Koye \& Winer [6] who compared their experimental results obtained on point contacts to minimum film thickness predictions by Hamrock \& Dowson [7], and who found a qualitative agreement only, with rather large deviations at high contact pressures. For highly loaded circular contacts, Smeeth \& Spikes [8] have obtained quite substantial differences between measurements of central and minimum film thicknesses and predictions by Hamrock \& Dowson [7], especially at high contact pressure where their measurements agree with Venner predictions [9]. On the basis of a wide set of experimental measurements, Chaomleffel et al. [10] evidenced an overall poor agreement with the minimum thickness predictions of Hamrock \& Dowson [7] and, on the other hand, a more satisfactory agreement with a model combining the approaches of Nijenbanning et al. [11] with that of Chevalier [12]. Finally, van Leeuwen [13-14] who, in reality, was trying to derive an appropriate value of the lubricant's pressure viscosity coefficient from combining film thickness 
measurements with different analytical expressions, indirectly showed the relative inaccuracies that the latter could generate.

In all of the above-mentioned works, rather significant discrepancies between measurements and predictions have therefore been noted, mainly concerning minimum film thicknesses. Wheeler et al. [15] summarized some of these discrepancies, on the basis of several reference cases, by comparison with their numerical predictions of the results obtained by 5 analytical models: Hamrock \& Dowson [7], Nijenbanning et al. and Chevalier [11-12], Evans \& Snidle [16], Chittenden et al. [17] and Masjedi \& Khonsari [18]. If on average Wheeler et al. found a relative deviation of about $10 \%$ on the central thickness, the deviation increases up to $40 \%$ for the minimum film thickness, with extreme values exceeding $90 \%$. To make things worse, all these deviations are of a nonconservative nature as they overestimate film thickness (both central and minimum values).

As for EHL numerical simulation, the solution of a contact case should be obtained after a complete convergence of the problem. However, this full convergence is not easy to achieve, especially when the contact is subjected to a high normal load and/or in the presence of very thin films. Under these conditions, the deformation of the elastic bodies becomes very large in comparison with the thickness of the lubricating film, which implies that calculations must be carried out with the highest degree of caution and accuracy. In addition, the almost exponential increase of viscosity with pressure generates a very strong non-linearity in the Reynolds equation. All this can explain why, in the literature, there are very few papers only that have reported validated results found under these conditions, compared to the countless film thickness values obtained at moderate pressure, typically $0.5 \mathrm{GPa}$ from steel/glass contacts. However, one can find works that have shown that controversies have erroneously arisen when the above precautions were not respected. This is the case, for example, of the publications of Morales-Espejel et al., Glovnea et al. and Venner [19-21] who collectively proved - experimentally and numerically - that film thickness decreases at a constant slope (on a log-log scale) when the entrainment speed is decreased. This has been verified even at high normal load or/and very low film thickness, any other tendency being only the consequence of errors, mainly due to inadequate mesh density in the case of numerical simulations.

Why minimum film thickness? The minimum film thickness is of primary interest to determine whether the separation of the contacting surfaces is ensured, which has a crucial importance on the useful life of lubricated mechanisms. If the separation is large enough, service life is likely to be long and limited, for instance, by surface fatigue. If the surfaces are not adequately separated, they interact by direct contacts, which result in shorter component life or even failure. In summary, the minimum film thickness is helpful to define the frontier between full-film, long term lubrication and other regimes in which direct interactions (i.e. contacts) between surfaces may occur. In that case, the first direct contacts between the surfaces precede the appearance of damages such as (non-exhaustive list), spalling fatigue, smearing, pitting, scuffing, wear, etc. 
It is therefore of primary importance to be capable of predicting and/or measuring this parameter, or the ratio of central to minimum film thickness with confidence. This ratio, if validated over a wide range of operating parameters, including those that characterize heavily loaded EHD contacts and those operated in the VTF regime, will be a powerful mean, not only for correctly predicting the minimum film thickness (from knowledge of the central one), but also for determining the lubrication regime. Note that at the current stage of knowledge on this question, it is imperative to carry out both approaches (i.e. prediction of the minimum film thickness directly, or from knowledge of the central one, using the central-to-minimum film thickness ratio) at the same time, or to compare them to each other, to ensure their coherence and the validity of the results..

This publication is the third part of a series (after [22-23]), which aims at clarifying or recalling some fundamental aspects of EHL, in order to stimulate the correct use of the tools, results or models available to date. This approach is intended to make EHL a rigorous and quantitative field of tribology, based on independently validated concepts and data, in opposition to the classical EHL approach, which too often leads to misinterpretations or results that cannot be extended or generalized.

\section{Quantitative minimum film thickness predictions}

\subsection{Brief description of the numerical model}

Quantitative minimum film thickness predictions are carried out in this work using the full-system finite element approach [24]. It consists in a simultaneous resolution of all governing equations of the isothermal Newtonian EHL problem. These are the Reynolds, linear elasticity and load balance equations. The first governs the hydrodynamic pressure build-up within the lubricating conjunction. The second governs the elastic deformation of the contacting solids under the influence of the generated pressure. The last equation ensures that the correct external load is applied to the contact, by balancing it with the integral of the pressure field generated within the lubricating film. This is achieved through a monitoring of the rigid-body separation of the contacting solids. A penalty method [25] is used to force any non-physical negative pressures arising in the solution of Reynolds equation to zero. Such pressures usually arise on the outlet side of the contact. But they cannot be tolerated by the lubricant, which will cavitate, leading to a break-up of the lubricating film. Also, stabilized finite element formulations [26] are employed for the solution of highly loaded contacts. All equations are discretized using finite elements and they are solved together in a monolithic system. Given the highly non-linear nature of the arising system of equations, a damped-Newton [27] procedure is employed in its resolution. All numerical tests were carried out on a sufficiently fine mesh to guarantee grid-independent results. For further details, the interested reader is referred to [24]. 


\subsection{Conditions}

The considered configuration is that of a steel-steel ball-on-disk contact under pure-rolling conditions, with a ball radius of $12.7 \mathrm{~mm}$. Perfectly smooth surfaces are assumed and isothermal Newtonian conditions are considered with an ambient temperature $T_{0}=30^{\circ} \mathrm{C}=303 \mathrm{~K}$. The contact load and mean entrainment speed are varied to cover a wide range of the Moes [28] dimensionless parameters $M$ and $L$, covering the grid $M=10,30,50,100,300,500,1000,2000$ and 3000 and $L=$ $1,2,3,5,7,10,15$ and 20 . The lubricant selected for the analysis is a well-characterized mineral oil, known under the commercial name "Shell T9". Its density-pressure dependence may be accurately represented by the Murnaghan [29] equation of state:

$$
\rho(p)=\rho_{0}\left[1+\frac{K_{0}^{\prime} p}{K_{00} \exp \left(-\beta_{K} T_{0}\right)}\right]^{\frac{1}{K_{0}}}
$$

The values for the different parameters of the Murnaghan equation of state for this fluid are [30]: $K_{0}^{\prime}=10.545, K_{00}=9.234 G P a, \beta_{K}=6.09 \times 10^{-3} K^{-1}$ and $\rho_{0}=872 \mathrm{~kg} / \mathrm{m}^{3}$. As for its viscositypressure dependence, it is accurately represented by the modified Yasutomi-WLF model [31]:

$$
\mu(p)=\mu_{g} \exp \left[\frac{-2.303 C_{1}\left(T_{0}-T_{g}\right) F}{C_{2}+\left(T_{0}-T_{g}\right) F}\right]
$$

$$
\text { with } \begin{aligned}
T_{g}(p) & =T_{g 0}+A_{1} \ln \left(1+A_{2} p\right) \\
& F(p)=\left(1+b_{1} p\right)^{b_{2}}
\end{aligned}
$$

In the above relation, $T_{g}$ is the glass transition temperature at a given pressure, with $T_{g 0}$ being its ambient-pressure value. The values for the different parameters of the modified Yasutomi-WLF model for Shell T9 are [30]: $A_{1}=188.95^{\circ} \mathrm{C}, A_{2}=0.53 G P a^{-1}, b_{1}=7.37 G P a^{-1}, b_{2}=-0.62, C_{1}=15.90$ , $C_{2}=14.16^{\circ} \mathrm{C}, T_{g 0}=-68.47^{\circ} \mathrm{C}$ and $\mu_{g}=10^{12} \mathrm{~Pa} \cdot \mathrm{s}$. This results in an ambient-pressure viscosity value $\mu_{0}=12.50 \mathrm{mPa} \cdot \mathrm{s}$ and a reciprocal asymptotic isoviscous pressure coefficient [32] $\alpha^{*}=21.21 G P a^{-1}$. This latter value is used as the pressure-viscosity coefficient in evaluating the Moes parameter $L$.

\subsection{Results}

Since $h_{c}$, the central film thickness can be accurately measured, or even estimated using several available models and given the historic failure of film thickness analytical formulae in accurately predicting minimum film thickness, most results are presented here in the form of a ratio of central to minimum film thickness $h_{c} / h_{m}$. Furthermore, since results are easier to present and discuss as a function of two dimensionless parameters (instead of three for those of Hamrock \& Dowson), the two 
Moes parameters, $M$ and $L$, are employed in the following to express and represent variations of the ratio $h_{c} / h_{m}$.

The dimensionless values (according to Moes [28]) of the central and minimum thicknesses, $H_{c}$ and $H_{m}$, are plotted in Figure 1 as a function of $M$ for different values of $L$. The corresponding values are tabulated in Appendix A. The same scaling of the axis system was used in the two graphs of Figure 1 to highlight the major difference between $H_{c}$ and $H_{m}$ variations. Clearly, whatever the $L$ value varying between 1 and 20, $H_{c}$ varies relatively little as a function of $M$ compared to $H_{m}$.

In addition, it is interesting to consider the variations of the central to minimum thickness ratio because i) it has the advantage of not being dependent on the non-dimensioning convention $\left(h_{c} / h_{m}=H_{c} / H_{m}\right)$ and ii) it provides a quick way of correctly estimating the minimum thickness from knowledge of a central thickness value that is easier to obtain experimentally or analytically, using film thickness formulae. The variations of this ratio for the considered values of $M$ and $L$ are given in Table 1 and plotted as a 3-D curve in Figure 2.

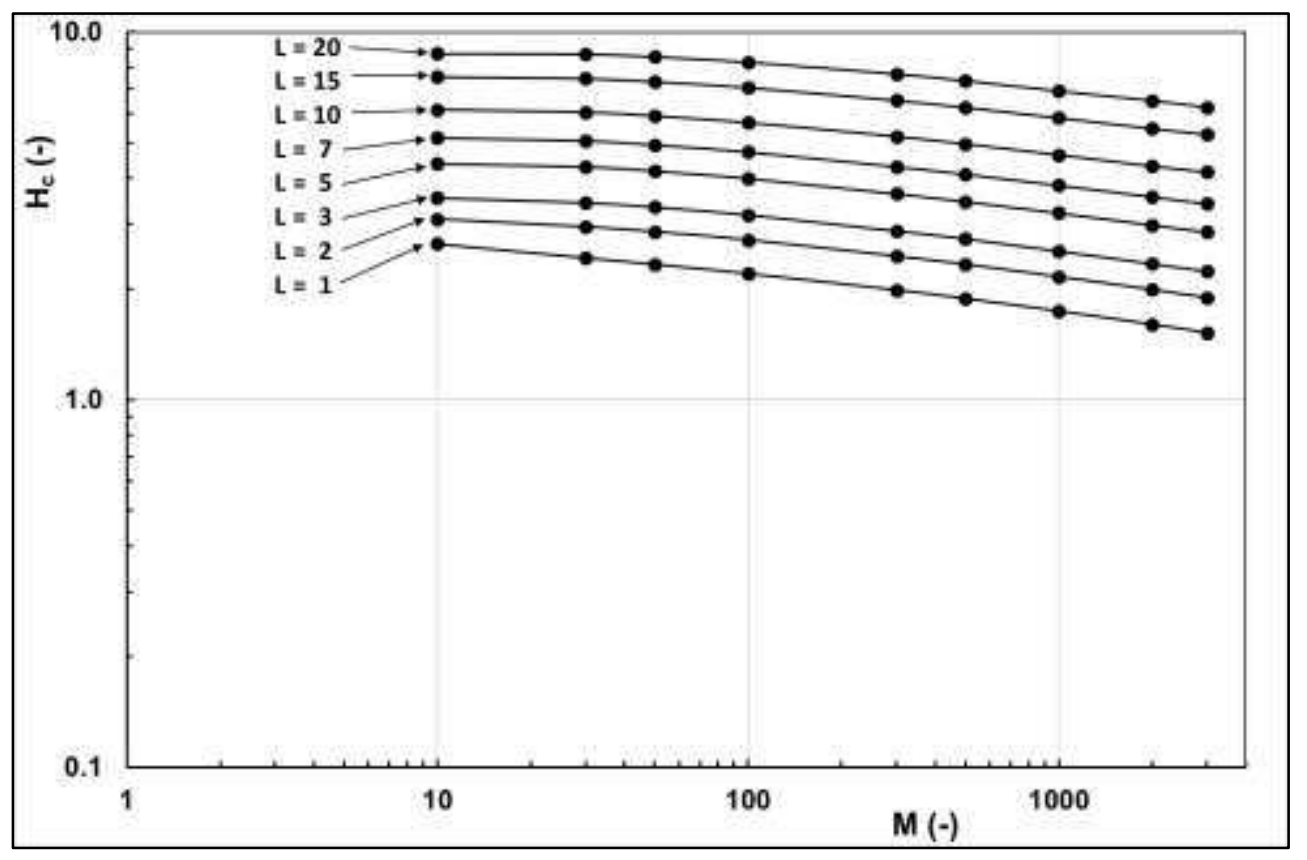




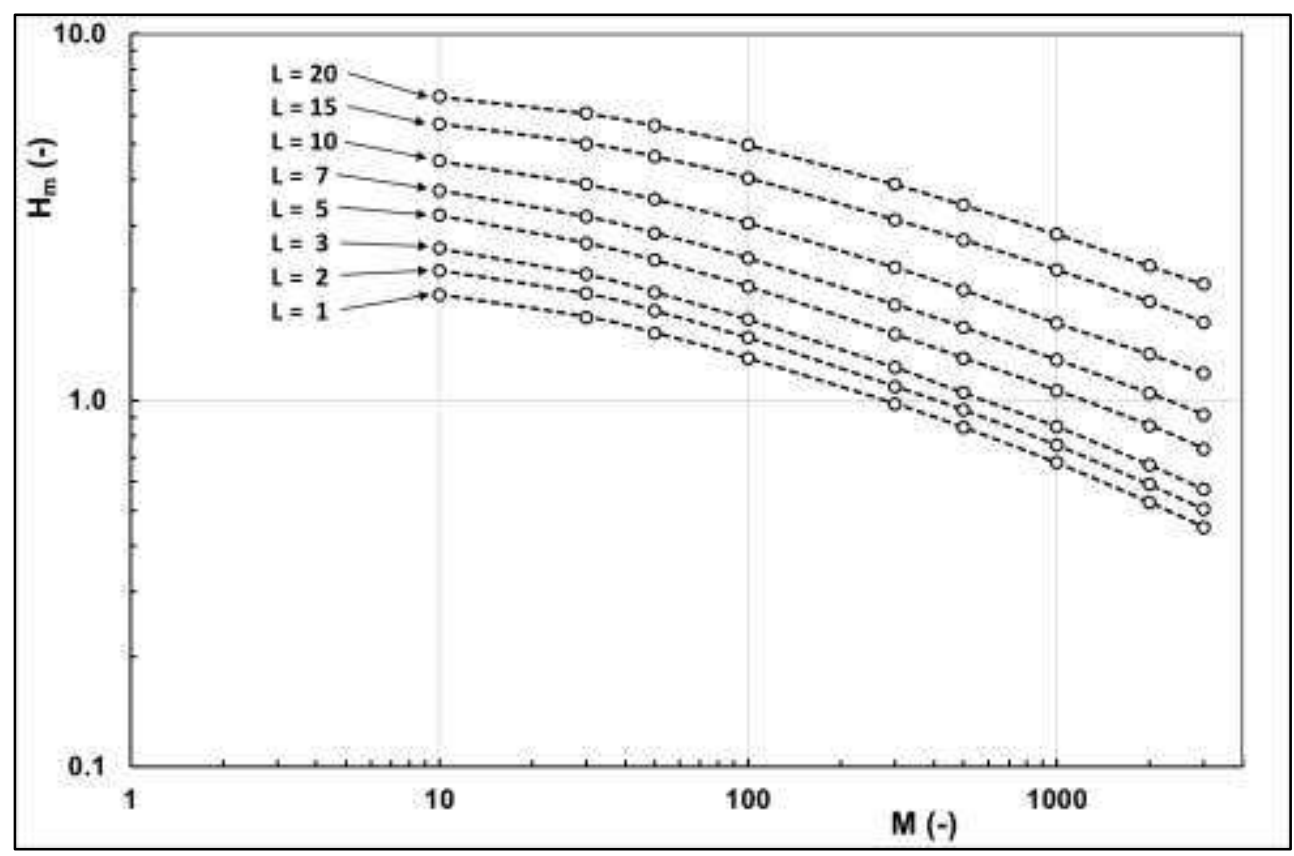

Figure 1: central (top) and minimum (bottom) dimensionless film thickness as a function of $M$ for different $L$ values.

\begin{tabular}{|c|c|c|c|c|c|c|c|c|c|}
\hline $\mathbf{L} \backslash \mathbf{M}$ & $\mathbf{1 0}$ & $\mathbf{3 0}$ & $\mathbf{5 0}$ & $\mathbf{1 0 0}$ & $\mathbf{3 0 0}$ & $\mathbf{5 0 0}$ & $\mathbf{1 0 0 0}$ & $\mathbf{2 0 0 0}$ & $\mathbf{3 0 0 0}$ \\
\hline $\mathbf{1}$ & 1.37 & 1.44 & 1.53 & 1.69 & 2.03 & 2.24 & 2.58 & 3.04 & 3.37 \\
\hline $\mathbf{2}$ & 1.37 & 1.51 & 1.63 & 1.83 & 2.25 & 2.48 & 2.86 & 3.38 & 3.76 \\
\hline $\mathbf{3}$ & 1.36 & 1.56 & 1.69 & 1.91 & 2.34 & 2.61 & 2.99 & 3.52 & 3.91 \\
\hline $\mathbf{5}$ & 1.37 & 1.60 & 1.74 & 1.95 & 2.40 & 2.65 & 3.03 & 3.50 & 3.88 \\
\hline $\mathbf{7}$ & 1.38 & 1.59 & 1.73 & 1.93 & 2.36 & 2.60 & 2.97 & 3.41 & 3.74 \\
\hline $\mathbf{1 0}$ & 1.37 & 1.56 & 1.67 & 1.86 & 2.26 & 2.48 & 2.85 & 3.24 & 3.52 \\
\hline $\mathbf{1 5}$ & 1.32 & 1.49 & 1.59 & 1.75 & 2.10 & 2.28 & 2.58 & 2.95 & 3.23 \\
\hline $\mathbf{2 0}$ & 1.30 & 1.44 & 1.52 & 1.67 & 1.98 & 2.16 & 2.43 & 2.79 & 3.00 \\
\hline
\end{tabular}

Table 1: variations of the $H_{c} / H_{m}\left(\right.$ or $\left.h_{c} / h_{m}\right)$ ratio as a function of $M$ and $L$. 


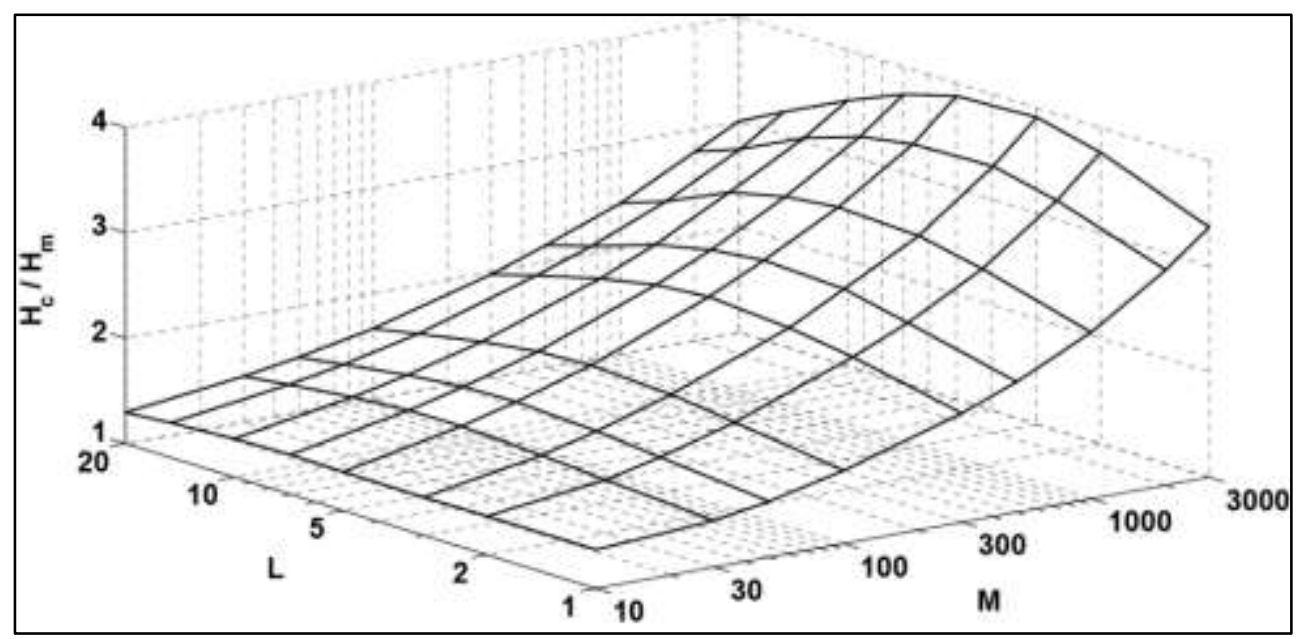

Figure 2: 3-D variations of the $H_{c} / H_{m}\left(\right.$ or $\left.h_{c} / h_{m}\right)$ ratio with $M$ and $L$.

\subsection{Analytical expression for $h_{c} / h_{m}$}

To provide a reliable means of estimating $h_{m}$ from a knowledge of $h_{c}$, the results in Table 1 have been treated in such a way as to obtain an analytical expression of $h_{c} / h_{m}$ as a function of $M$ and $L$, representative of the numerical results and, of course, covering a wide domain of application. Given the smooth nature of the $h_{c} / h_{m}$ surface on a $\ln (M)-\ln (L)$ scale, it would only be natural to attempt the curve fit as a function of $\widetilde{M}=\ln (M)$ and $\tilde{L}=\ln (L)$. The following formula ensues over the considered domain of application $M \in[10,3000]$ and $L \in[1,20]$, with a coefficient of determination (R-Squared) of 0.998 , obtained from the 72 data points given in Table 1:

$$
\begin{gathered}
h_{c} / h_{m}=1.267+\mathcal{F}(\tilde{L}) \cdot \widetilde{M}^{\mathcal{G}(\widetilde{L})} \\
\text { with } \quad \widetilde{M}=\ln (M), \tilde{L}=\ln (L) \\
\mathcal{F}(\tilde{L})=-0.0006315 . \tilde{L}^{3}+0.001005 . \tilde{L}^{2}+0.004697 . \tilde{L}+0.00537 \\
\mathcal{G}(\tilde{L})=0.02689 . \tilde{L}^{2}-0.2376 . \tilde{L}+2.859
\end{gathered}
$$

\section{Comparisons and validation}

\subsection{Previous works and expressions}

A large number of analytical expressions predicting central and minimum film thicknesses in EHD circular contacts have been published in the literature; some more widely used than others; some more reliable than others without any correlation between their usage and accuracy. The domains over which they have been established (described here by the parameters $M$ and $L$ ) are quite 
different from one fomula to another. They will be mentioned to point out the limitations of the formulas and to underline that, in many circumstances, these models have been used far beyond their domain of validity, leading to widely extrapolated film thickness values with no guarantee of their accuracy.

Three analytical models are considered here:

- Hamrock \& Dowson [7], which are certainly the most used in the literature, initially established for $M \in[25-500]$ and $L \in[5-15]$,

- Chittenden et al. [17], which have extended the former on $M \in[20-500]$ and $L \in$ [3-15], and have shown a better estimation of the central film thickness [15],

- Masjedi \& Khonsari [18], which are among the most recent and cover a wide domain especially in $\mathrm{M}: M \in[15-10000]$ and $L \in[5-20]$.

Note that the above-mentioned analytical film thickness formulas have been originally derived for the general case of a point contact (circular or elliptical), and they have been adjusted here to only consider the particular case of a circular contact (i.e. unit ellipticity ratio).

In addition, three further contributions that directly report the variations of the $h_{c} / h_{m}$ ratio are included:

- Chevalier [12] who was probably the first to tabulate the $h_{c} / h_{m}$ ratio over wide ranges of $M$ and $L(M \in[10-1000]$ and $L \in[0-20])$,

- Sperka, Krupka and Hartl [33] who published tables of the $h_{c} / h_{m}$ ratios for various pressureviscosity coefficient values and a regression of this ratio as a function of $\alpha_{\text {film }}, M$ and $L$ for $M \in$ [2-1000] and $L \in[1-25]$,

- This work where $M$ and $L$ were varied as follows: $M \in[10-3000]$ and $L \in[1-20]$.

The central and minimum film thickness expressions are reported in Appendix $B$, together with the original Chevalier and Sperka et al. (for $\alpha_{f i l m}=20.6 \mathrm{GPa}^{-1}$ ) tables. Below are reported the expressions of the $h_{c} / h_{m}$ ratio that can be deduced from the three analytical models, the formula proposed by Sperka et al. [33] is given in Appendix B:

Hamrock \& Dowson [7]

$$
h_{c} / h_{m}=1.048 U^{-0.01} G^{0.04} W^{0.006}
$$

Chittenden et al. [17]

$$
h_{c} / h_{m}=1.697
$$

Masjedi \& Khonsari [18]

$$
h_{c} / h_{m}=3.230 U^{-0.048} G^{-0.148} W^{0.045}
$$


There are still significant disparities between the above three analytical models for $h_{c} / h_{m}$. First, in the central and minimum film thickness formulas of Chittenden et al., the dimensionless parameters $U, G$ and $W$ have the same exponents. Consequently, the ratio $h_{c} / h_{m}$ remains constant and equal, for circular contacts, to 1.697. For the Hamrock \& Dowson model, the exponents assigned to $U, G$ and $W$ for estimating $h_{c} / h_{m}$ are very low: this leads to weak variations of the film thickness ratio. It is somehow really surprising to face these trends, which do not reflect the countless film thickness experimental results published for at least 4 decades. The latter have clearly shown that, when the entrainment speed decreases over a sufficiently large range, the minimum film thickness reduction is significantly greater than the reduction in central film thickness. Therefore, the ratio $h_{c} / h_{m}$ should increase substantially. Numerical simulations of the EHD contact have obviously confirmed this observation. Figure 3 of Venner's publication [21] is one example among many. The author reported power law regressions that allow quantifying, for the selected two fluids and operating conditions, the variation of the $h_{c} / h_{m}$ ratio versus $u_{e}$ (and thus, versus $U$ ) by a power law with an exponent of $-0.20 \pm 0.01$.

Finally, the exponents in the Masjedi \& Khonsari model are larger and should give larger and thus, more realistic variations in the $h_{c} / h_{m}$ ratio than the two previous models.

\subsection{Comparisons with previous models}

The comparison of the six models and tables is presented in two formats. On the one hand, in Figure 3 where $M$ varies from 10 to 3000 and $L$ takes the values of 2, 5, 10 and 20, when these values do not exceed the domains over which the models were established. Otherwise, the curves are limited to the boundaries of the domains over which the models were based. On the other hand, Table 2 summarizes the $h_{c} / h_{m}$ ratios for 4 representative pairs of $M$ and $L$ values; $M=30 \& L=5$; $M=$ $30 \& L=20 ; M=1000 \& L=5 ; M=1000 \& L=20$. To present results obtained under identical conditions and make comparisons possible, the domains used by Hamrock \& Dowson and those of Chittenden et al. have been slightly extended for this table (in a reasonable way): $M$ from 500 to 1000 , and $L$ from 15 to 20.
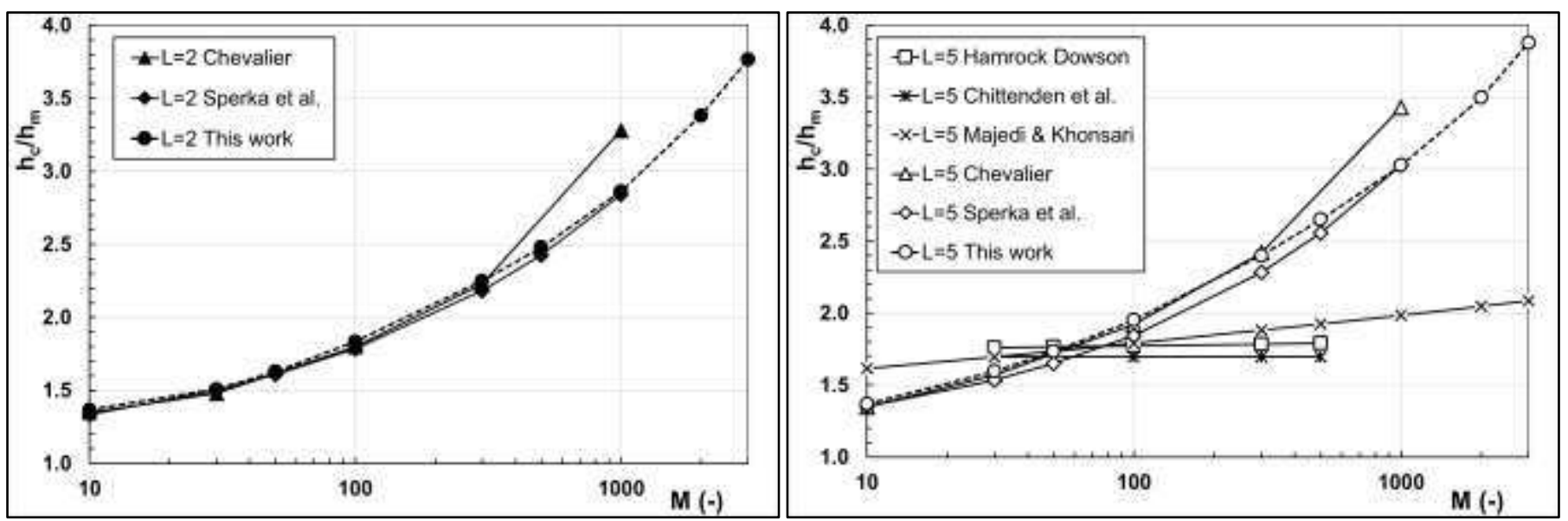

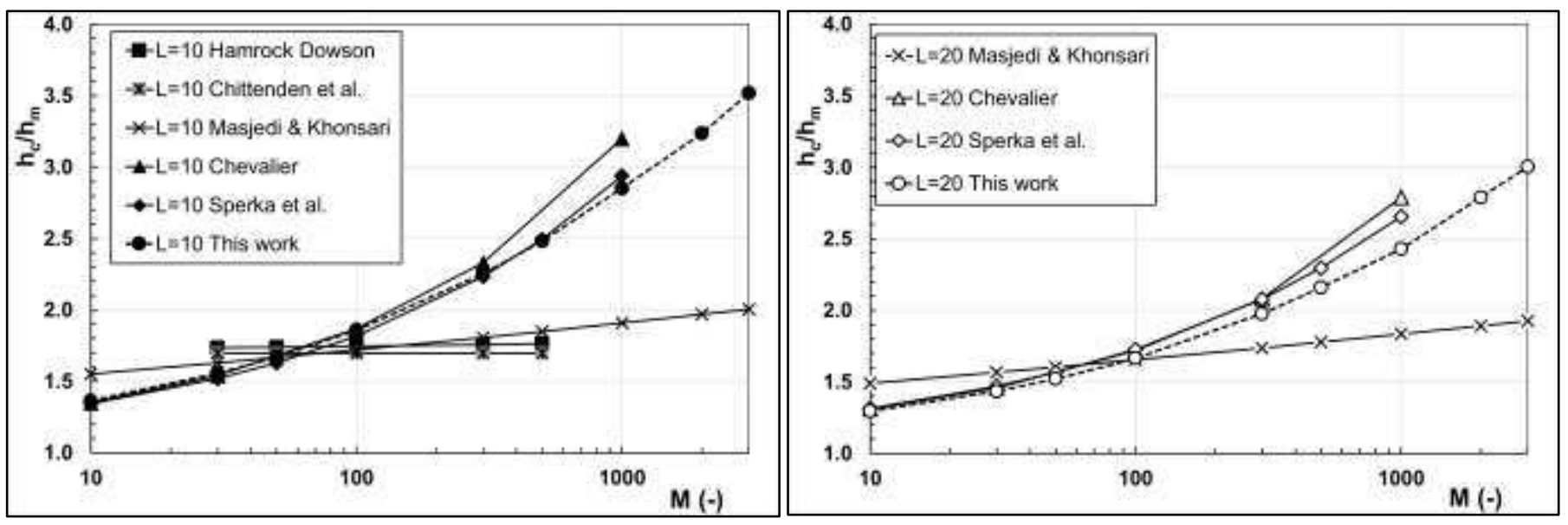

Figure 3: variations of the $h_{c} / h_{m}$ ratio versus $M$ for $L=2, L=5$ (top row), $L=10, L=20$ (bottom row) for 3 analytical film thickness models (Hamrock \& Dowson [7], Chittenden et al. [17], Masjedi \& Khonsari [18]), the approaches of Chevalier [12], Sperka et al. [33] and this work (plotted with dotted lines).

\begin{tabular}{|l|c|c|c|c|}
\hline & $\begin{array}{c}M=\mathbf{3 0} \\
\boldsymbol{L}=\mathbf{5}\end{array}$ & $\begin{array}{c}\boldsymbol{M}=\mathbf{3 0} \\
\boldsymbol{L}=\mathbf{2 0}\end{array}$ & $\begin{array}{c}\boldsymbol{M}=\mathbf{1 0 0 0} \\
\mathbf{L}=\mathbf{5}\end{array}$ & $\begin{array}{c}\boldsymbol{M}=\mathbf{1 0 0 0} \\
\boldsymbol{L}=\mathbf{2 0}\end{array}$ \\
\hline Hamrock \& Dowson & 1.76 & 1.71 & 1.80 & 1.74 \\
\hline Chittenden et al. & \multicolumn{5}{|c|}{1.70} \\
\hline Masjedi \& Khonsari & 1.70 & 1.57 & 2.00 & 1.84 \\
\hline Chevalier & 1.57 & 1.46 & 3.43 & 2.79 \\
\hline Sperka et al. & 1.54 & 1.47 & 3.03 & 2.66 \\
\hline This work & 1.60 & 1.44 & 3.03 & 2.43 \\
\hline
\end{tabular}

Table 2: $h_{c} / h_{m}$ ratios for 4 representative pairs of $M$ and $L$ values predicted by 3 analytical film thickness models (Hamrock \& Dowson* [7], Chittenden et al. * [17], Masjedi \& Khonsari [18]), the numerical approaches of Chevalier [12], Sperka et al. [33] and this work.

* Slightly extended to $M=1000$ and $L=20$.

The four graphs in Figure 3 show a rather wide dispersion of the values given by the three analytical models and the three numerical ones. Apart for $40 \leq M \leq 100$, which is not a domain of great interest in this work, substantial differences are visible between the two approaches. Analytical expressions, whether recent or old, widely used (like Hamrock \& Dowson) or not, are unable to capture the significant increase in the $h_{c} / h_{m}$ ratio when $M$ increases. The deviations are particularly large for $M=1000$ (see Table 2) and are even more pronounced for $M=3000$ (see Figure 3) where the approach adopted in this work indicates a ratio of the order of $\approx 3.8$ for the most severe cases $(L=$ 2 or 5 ), while the analytical models predict a ratio of the order of 1.7 to 2 . This occurs in the case of 
highly loaded EHD contacts or at very thin film thickness. These are typical cases where the determination of $h_{m}$ is most critical in determining whether or not a full lubricating film can be generated and an over-prediction can lead to significant surface damage.

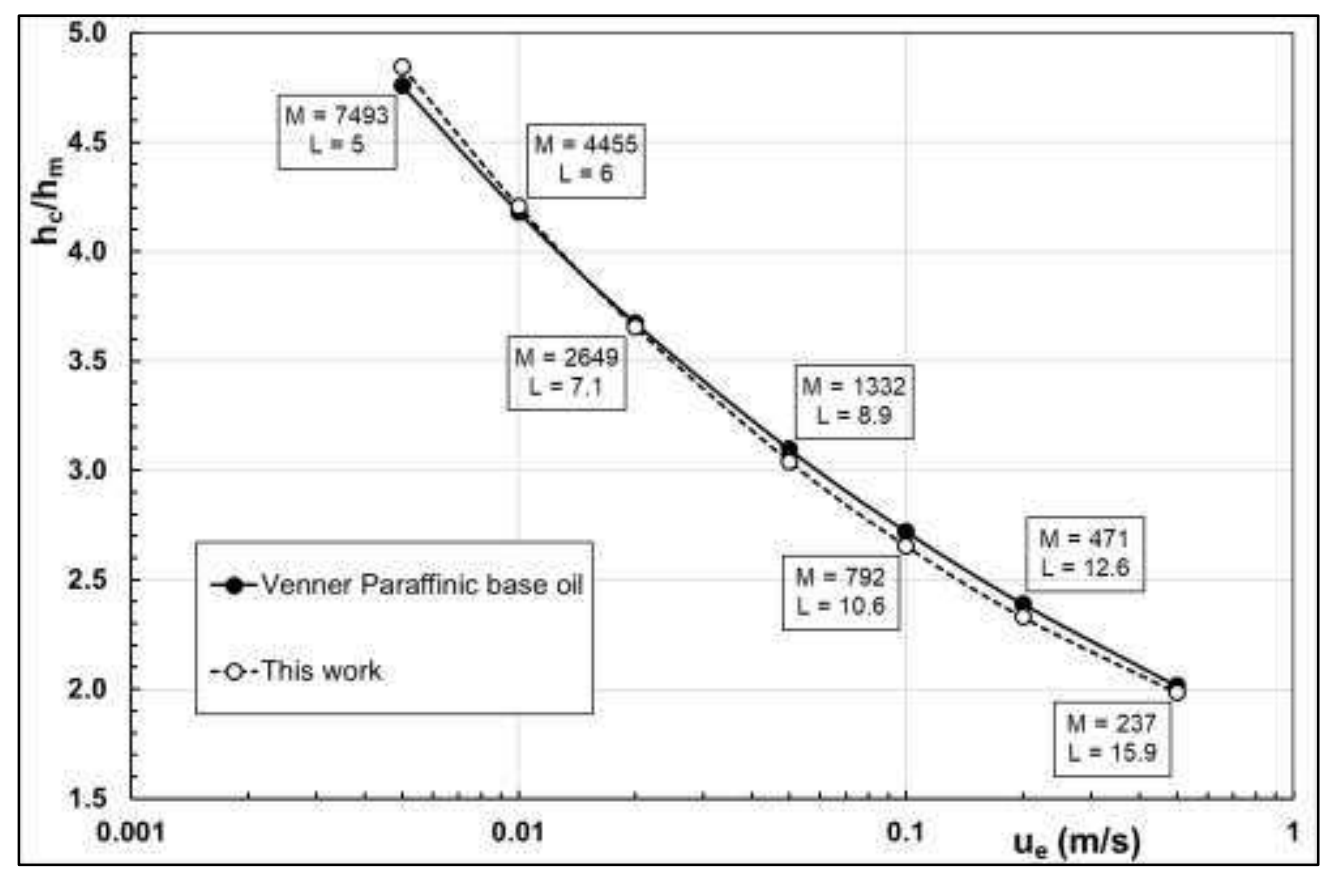

Figure 4: comparison of $h_{c} / h_{m}$ ratios predicted from Venner [21] for a paraffinic base oil with those derived from this work (using the analytical formula of section 2.4).

An additional comparison with numerical results is shown in Figure 4. Venner published results obtained over large $M$ and $L$ ranges and down to very small film thickness values [21]. Furthermore he showed that both $h_{c}$ and $h_{m}$ varied as power functions of $u_{e}$, the entrainment speed, making it easy to express the $h_{c} / h_{m}$ ratio as a power function of this parameter. However, in his simulations, Venner used the Roelands pressure-viscosity equation and the Dowson \& Higginson compressibility formula. In theory, these two models differ from those described earlier in this work. However, the Hertzian pressure chosen by Venner is not too large (1.5 GPa) and the difference between Dowson \& Higginson and Murnagham predictions is not really prohibitive. Moreover, Venner simulated two lubricants, among them a paraffinic base oil whose piezoviscosity is described in a rather close way by the Roelands and modified Yasutomi-WLF models in the low-to-medium pressure domain, which is critical for the generation of EHD film thickness. For this latter lubricant, the film thickness ratio varies as follows according to Venner [21]:

$$
h_{c} / h_{m}=1.7711 u_{e}^{-0.1865}
$$


Although using different physical and rheological equations, and despite an extension of the analytical formula of section 2.4 beyond its domain of application (for $u_{e}<0.01 \mathrm{~m} / \mathrm{s}$ ), the agreement with Venner's results is excellent. The average relative deviation between the two models on the cases plotted in Figure 4 is slightly less than 1\%. This comparison really covers cases with very high $M$ and low $L$ (both values are given in Figure 4): $M$ reaches almost 7500 and $L=5$ for the lowest entrainment velocity, $u_{e}=0.005 \mathrm{~m} / \mathrm{s}$.

\subsection{Comparison and validation against experiments}

Experimental validation is certainly the most reliable way to validate results from numerical simulations. Experiments were performed on a steel ball/sapphire disk contact [35], under purerolling conditions with smooth surfaces at $T=50^{\circ} \mathrm{C}$. The contact was lubricated with a wellcharacterized lubricant, 5P4E ( $\mu=160 \mathrm{mPa} . \mathrm{s}$ and $\alpha^{*}=28.4 \mathrm{GPa}^{-1}$ at $\left.50^{\circ} \mathrm{C}\right)$. The tests were conducted at variable entrainment speed, for different applied normal loads leading to Hertzian pressures ranging from 0.76 to $1.8 \mathrm{GPa}$. These operating conditions lead to values of $L$ varying from 14 to 23 when $u_{e}$ varies from 0.1 to $0.63 \mathrm{~m} / \mathrm{s}$, regardless of the Hertzian pressure.

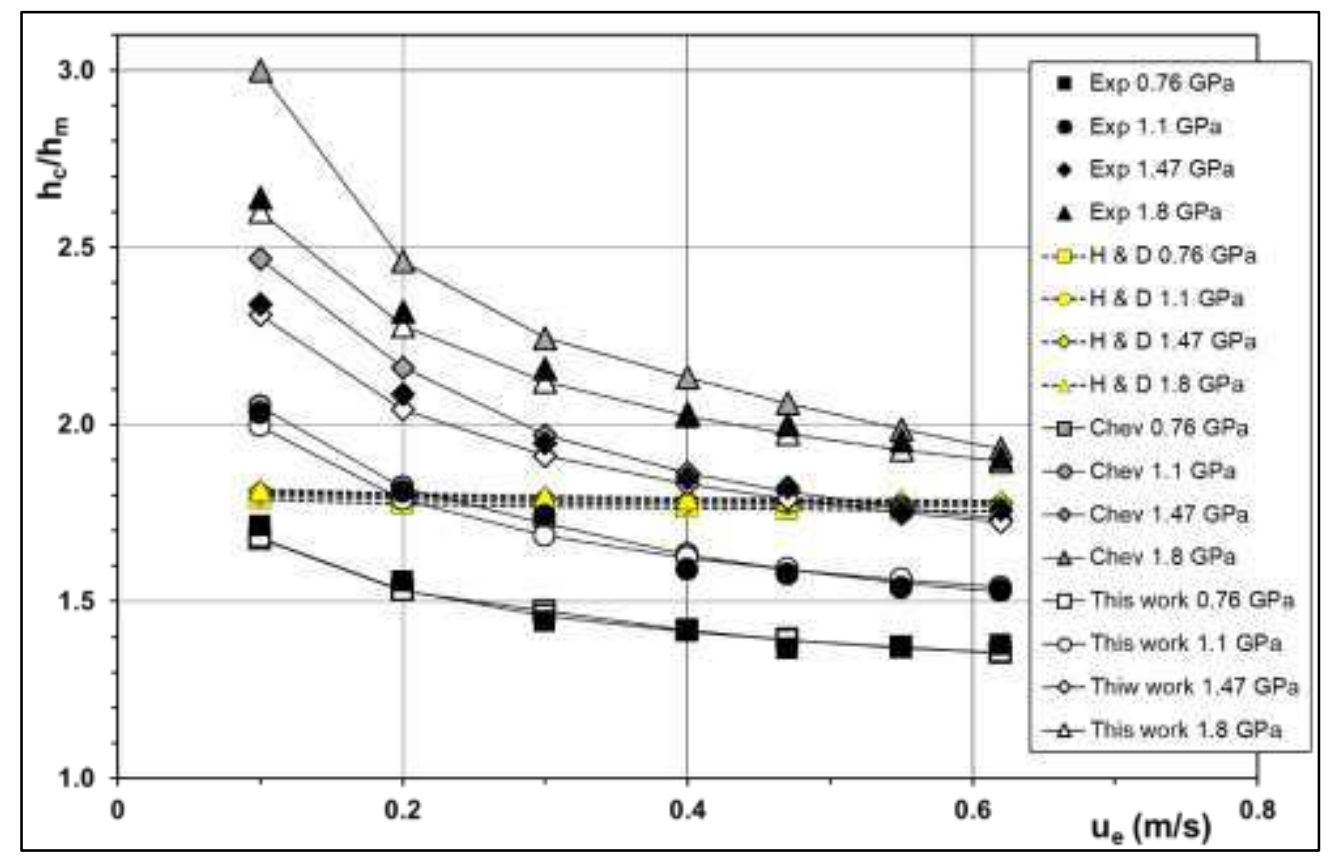

Figure 5: comparison between measurements (black symbols) of $h_{c} / h_{m}$ on $5 P 4 E$ at $50^{\circ} \mathrm{C}$, for different contact pressures and entrainment velocities $u_{e}$, with predictions from Hamrock-Dowson, Chevalier (noted here H\& D and Chev, respectively) and this work (white symbols).

In Figure 5, experimental results are compared to the Hamrock \& Dowson and Chevalier predictions, together with simulation results from this work (obtained using the analytical formula of section 2.4). Apart from the values given by Hamrock \& Dowson that are nearly independent of $u_{e}$ and $p_{H}$, we 
note that the film thickness ratio increases continuously when $u_{e}$ decreases, irrespective of the Hertzian pressure. Two cases can be distinguished.

- For $p_{H}$ equal to 0.76 and $1.1 \mathrm{GPa}$, we can conclude that both the predictions of Chevalier and this work are in good agreement with the experimental results. Nevertheless, this agreement corresponds to rather low to medium values of $M$, lying in the ranges [18 - 70] and [55 - 218], respectively.

- In contrast, when $p_{H}$ is equal to 1.47 and $1.8 \mathrm{GPa}$, an increasing discrepancy is observed between, on one side the experimental values and the predictions of this work and, on the other side, the predictions of Chevalier. The latter increasingly overestimate the $h_{c} / h_{m}$ ratio, while predictions from this work remain in very good agreement with experiments. This change in trend is observed for medium to high $M$ values lying in the ranges [131 - 514] and [249-978], for $p_{H}=1.47$ and $1.8 \mathrm{GPa}$ respectively.

These comparisons with experiments are instrumental because they validate the numerical approach developed in this work. Nevertheless, they remain limited to high, but not extreme, values of $M$ and to rather large values of $L$. A second series of comparisons between experiments and simulations will allow to check the validity of the model in more extreme and representative cases.

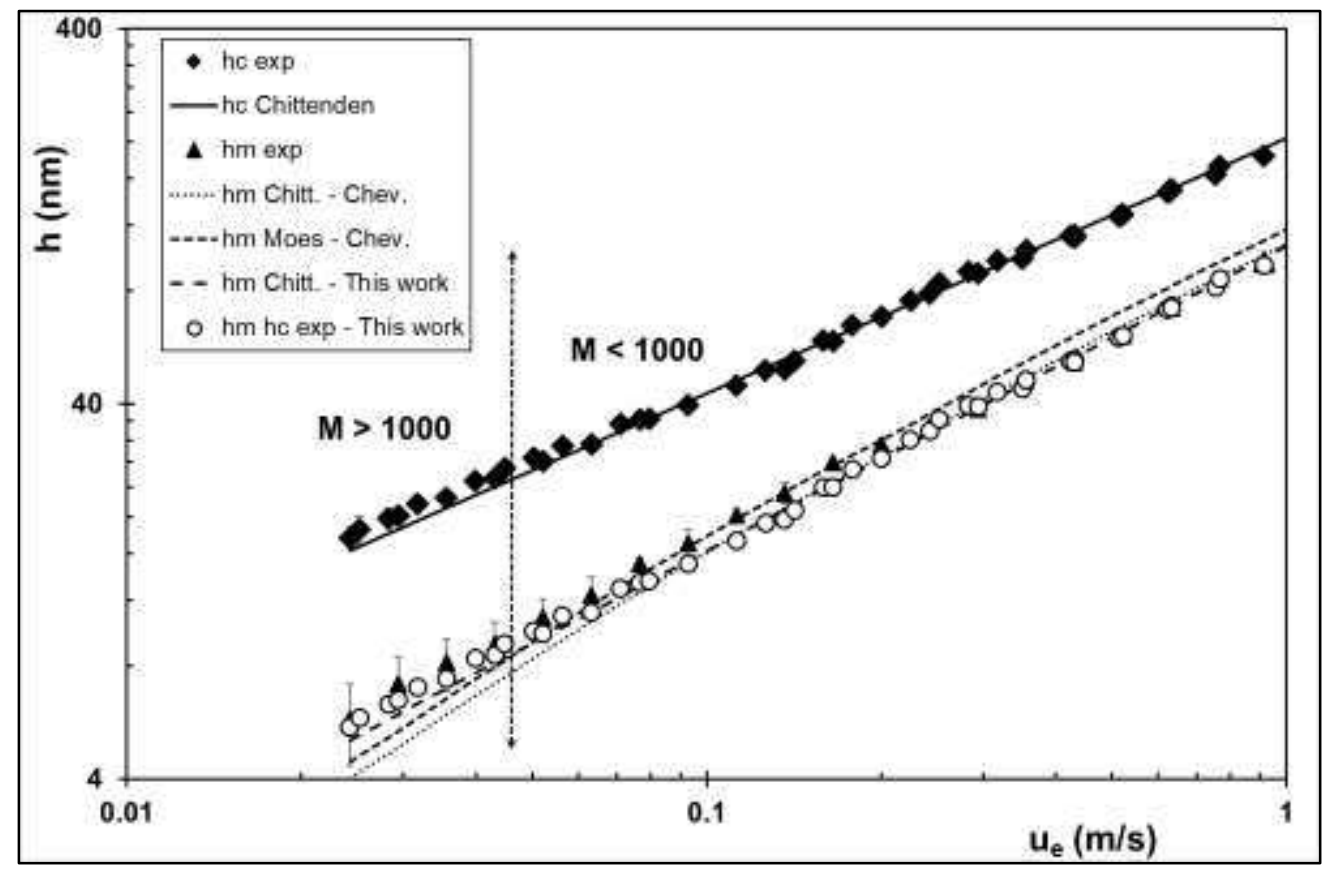

Figure 6: comparison between measurements of central and minimum film thicknesses (black symbols) on a mineral base oil at $25^{\circ} \mathrm{C}$ for a wide range of entrainment velocities $u_{e}$, with several predictions, purely numerical or hybrid, mixing experimental results and numerical models.

Experimental results were taken from Ref. [5] where a hydrocracked mineral base oil (Yubase 4) was proven to generate film thickness down to a few nanometers without deviating from a linear 
dependence (on a log-log scale) on the entrainment speed, thus following a power law with a constant exponent. Tests were performed on a ( $\mathrm{SiO}_{2}$-coated or not) glass disk in contact with a steel ball under pure-rolling conditiosn and smooth surfaces at $p_{H}=0.5 \mathrm{GPa}$. They were conducted at $T=25^{\circ} \mathrm{C}\left(\mu=28 \mathrm{mPa}\right.$.s and $\alpha=16.6 \mathrm{GPa}^{-1}$ at $\left.25^{\circ} \mathrm{C}\right)$ for different entrainment speeds ranging from $1 \mathrm{~m} / \mathrm{s}$ down to $0.02 \mathrm{~m} / \mathrm{s}$.

As in Figure 5, experimental results are plotted with black symbols. $h_{c \text { exp }}$ is compared with the Chittenden predictions which gave the closest estimation of the central film thickness [5]. As for $h_{m}$, different scenarios were considered:

- The Chevalier $h_{c} / h_{m}$ ratio was applied to the $h_{c}$ prediction by the Chittenden equation [17] (noted "hm Chitt. - Chev." in Figure 6). Although giving a good agreement in the middle-to-high entrainment speed domain, this leads to the largest underestimation of the experimental minimum film thickness for the lower $u_{e}$ values, i.e. in the more critical cases.

- The Chevalier $h_{c} / h_{m}$ ratio was applied to the $h_{c}$ prediction by the Nijenbanning, Venner and Moes [11] equation (noted "hm Moes - Chev." in Figure 6). In agreement with our previous works (see [10] for instance), this scenario yields, on average, a rather correct prediction of $h_{m}$. But in detail, we note an overestimation of $h_{m}$ at high entrainment speeds and an underestimation at low speeds. Thus, the predicted slope of $h_{m}=f\left(u_{e}\right)$ does not quantitatively agree with the experimental one.

- This work $h_{c} / h_{m}$ ratio was applied to the $h_{c}$ prediction by the Chittenden expression (noted "hm Chitt. - This work" in Figure 6). In that case, the minimum film thicknesses at medium-to-high entrainment speeds are in very good agreement with the experimental values, and those at low speeds are slightly underestimated.

- Finally, the experimental central film thicknesses were divided by the $h_{c} / h_{m}$ ratios from this work and noted "hm hc exp - This work" in Figure 6. This hybrid combination of experimental results and numerical model leads to the best agreement with the $h_{m}$ measurements, regardless of the entrainment velocity.

This last scenario is of particular interest. Not only does the method allow a reliable prediction of $h_{m}$, but it prevents its experimental measurement or calculation by an analytical expression, both of which can be relatively inaccurate. At low entrainment speeds, $M$ becomes greater than 1000 (as highlighted in Figure 6) and simultaneously $L$ takes a very low value, here less than 2 when $u_{e}=$ $0.024 \mathrm{~m} / \mathrm{s}$. This reveals the robustness of the proposed approach, even in the very-thin-film regime.

\section{Summary}

This work presents a quantitative analysis of the prediction of minimum film thickness in elastohydrodynamic circular contacts. In contrast to central film thickness, minimum film thickness can be hard to accurately measure and it is poorly predicted by the classical EHL formulas. A 
particular focus has been put on the conditions, nowadays very common in lubricated mechanisms, which lead to highly loaded contacts ort/and low or very low film thicknesses.

An advanced numerical model was used to establish the variations of the central-to-minimum film thickness ratio as a function of the dimensionless parameters $M$ and $L$, and an analytical expression was derived.

The latter was compared to the classical film thickness formulas and to more recent similar expressions. The comparisons have confirmed the inability of the former to predict minimum film thickness, and the limitations of the latter, which tend to overestimate the $h_{c} / h_{m}$ ratio and thus to underestimate $h_{m}$ from knowledge of $h_{c}$. In addition, an excellent agreement was found with simulations published by Venner.

The validation of this work was achieved by comparisons with experimental results, with a focus on highly loaded and thin thin-films cases. The analytical model from this work has proved its capability to accurately predict the $h_{c} / h_{m}$ ratio under these conditions.

In conclusion, a reliable and validated method is proposed to predict the minimum film thickness in circular EHD contacts, from knowledge of central film thickness, which can be either accurately measured or rather well estimated using classical film thickness formulae. The proposed approach can be of particular interest to experimental researchers, or also design engineers wishing to assess the actual operating conditions of a lubricated contact from the macroscopic parameters.

\section{Declarations}

Funding. This work receives no funding.

Conflict of interests. The authors declare that they have no conflict of interests.

Availability of data and material (data transparency). The authors declare that all data supporting the findings of this study are available within the article.

Authors' contributions. $\mathrm{WH}$ and PV conceived the project. WH performed the simulations. PV prepared the bibliography and found data for the comparisons. WH and PV wrote the manuscript. 


\section{References}

[1] Albahrani S., Philippon D., Vergne P., Bluet J.: A review of in situ methodologies for studying elastohydrodynamic lubrication. Proc. Inst. Mech. Eng. Part J: J. Eng. Tribol. 230, 1, 86-110 (2016) [2] Luo, J., Wen, S., Huang, P.: Thin film lubrication part I: study on the transition between EHL and thin film lubrication using a relative optical interference intensity technique. Wear 194, 107-115 (1996)

[3] Molimard J.: Etude expérimentale du régime de lubrification en film mince - application aux fluides de laminage, PhD thesis (in French). Institut National des Sciences Appliquées de Lyon. Nº d'ordre: 99ISAL0121 (1999)

[4] Ma, L., Luo, J.: Thin film lubrication in the past 20 years. Friction 4, 4, 280-302 (2016)

[5] Cusseau P., Vergne P., Martinie L., Philippon D., Devaux N., Briand F.: Film forming capability of polymer-base oil lubricants in elastohydrodynamic and very thin film regimes. Tribol. Lett. 67, 2, paper 45 (2019)

[6] Koye K.A., Winer W.O.: An experimental evaluation of Hamrock and Dowson minimum film thickness equation for fully flooded EHD point contacts. J. of Lubr. Technol. 103, 2, 284-294 (1981) [7] Hamrock B.J., Dowson D.: Isothermal elastohydrodynamic lubrication of point contacts Part III - Fully flooded results. J. of Lubr. Technol. 99, 2, 264-276 (1977)

[8] Smeeth M., Spikes H.A.: Central and minimum elastohydrodynamic film thickness at high contact pressure. J. of Tribol. 117, 291-296 (1997)

[9] Venner C.H.: Multilevel solution of the EHL line and point contact problems. PhD thesis, Twente University (1991)

[10] Chaomleffel J.P., Dalmaz G., Vergne P.: Experimental results and analytical predictions of EHL film thickness. Tribol. Inter. 40, 10-12, 1543-1552 (2007)

[11] Nijenbanning G., Venner C.H., Moes H.: Film thickness in elastohydrodynamically lubricated elliptic contacts. Wear 176, 217-229 (1994)

[12] Chevalier F.: Modélisation des conditions d'alimentation dans les contacts élastohydrodynamiques ponctuels. PhD thesis in French, INSA de Lyon, France, n 96 ISAL 0124 (1996)

[13] van Leeuwen $H .:$ The determination of the pressure-viscosity coefficient of a lubricant through an accurate film thickness formula and accurate film thickness measurements. Proc. IMechE, Part J: J. of Eng. Tribol. 223, 8, 1143-1163 (2009)

[14] van Leeuwen $\mathrm{H}$.: The determination of the pressure-viscosity coefficient of a lubricant through an accurate film thickness formula and accurate film thickness measurements. Part 2: high L values. Proc. IMechE, Part J: J. of Eng. Tribol. 225, 6, 449-464 (2011)

[15] Wheeler J.D., Vergne P., Fillot N., Philippon D.: On the relevance of analytical film thickness EHD equations for isothermal point contacts: qualitative or quantitative predictions? Friction 4, 4, 369-379 (2016) 
[16] Evans P., Snidle R.: The isothermal elastohydrodynamic lubrication of spheres. J. of Lubr. Technol. 103, 547-557 (1981)

[17] Chittenden R.J., Dowson D., Dunn J.F., Taylor C.M.: A theoretical analysis of the isothermal elastohydrodynamic lubrication of concentrated contacts - Part 2: General case, with lubricant entrainment along either principal axis of the Hertzian contact ellipse or at some intermediate angle. Proc. R. Soc. London A397, 271-294 (1985)

[18] Masjedi M., Khonsari M.M.: On the effect of surface roughness in point-contact EHL: Formulas for film thickness and asperity load. Tribol. Inter. 82(A), 228-244 (2015)

[19] Morales-Espejel G.E., Dumont M.L., Lugt P.M., Olver A.V.: A Limiting Solution for the Dependence of Film Thickness on Velocity in EHL Contacts with Very Thin Films. Tribol. Trans 48, 3, 317-327 (2005)

[20] Glovnea R.P., Olver A.V, Spikes H.A.: Experimental Investigation of the Effect of Speed and Load on Film Thickness in Elastohydrodynamic Contact. Tribol. Trans. 48, 3, 328-335 (2005)

[21] Venner C.H.: EHL film thickness computations at low speeds: risk of artificial trends as a result of poor accuracy and implications for mixed lubrication modelling. Proc. IMechE, Part J: J. of Eng. Tribol. 219, 285-290 (2005)

[22] Vergne P., Bair S.: Classical EHL versus Quantitative EHL: A Perspective - Part I: Real viscosity-pressure dependence and the viscosity-pressure coefficient for predicting film thickness. Tribol. Lett. 54, 1, pp. 1-12 (2014)

[23] Bair S., Martinie L., Vergne P.: Classical EHL versus Quantitative EHL: A Perspective Part II - Super-Arrhenius Piezoviscosity, An Essential Component of Elastohydrodynamic Friction Missing from Classical EHL. Tribol. Lett. 63, 3, 37 (2016)

[24] Habchi W.: Finite Element Modeling of Elastohydrodynamic Lubrication Problems. Wiley, Chichester, UK, ISBN: 978-1-119-22512-6 (2018)

[25] Wu S.R.: A Penalty Formulation and Numerical Approximation of the Reynolds-Hertz Problem of Elastohydrodynamic Lubrication. Int. J. of Eng. Sc. 24, 6, pp. 1001-1013 (1986)

[26] Habchi W., Eyheramendy D., Vergne P. and Morales-Espejel G.E.: Stabilized Fully-Coupled Finite Elements for Elastohydrodynamic Lubrication Problems. Adv. in Eng. Software 46, pp. 4-18 (2012)

[27] Deuflhard P.: Newton Methods for Nonlinear Problems, Affine Invariance and Adaptive Algorithms. Springer, Germany (2004)

[28] Moes H.: Optimum Similarity Analysis with Applications to Elastohydrodynamic Lubrication. Wear, 159, pp. 57-66 (1992)

[29] Murnaghan F.D.: The Compressibility of Media under Extreme Pressures. Proc. of the Nat. Acad. of Sc. 30, pp. 244-247 (1944)

[30] Wheeler J.-D., Molimard J., Devaux N., Philippon D., Fillot N., Vergne P., Morales-Espejel G.E.: A Generalized Differential Colorimetric Interferometry Method: Extension to the Film Thickness Measurement of Any Point Contact Geometry, Tribol. Trans. 61,4, pp. 648-660 (2018) 
[31 Bair S., Mary C., Bouscharain N., Vergne P.: An Improved Yasutomi Correlation for Viscosity at High Pressure. Proc. IMechE, Part J: J. of Eng. Tribol. 227, 9, pp. 1056-1060 (2013)

[32] Blok $\mathrm{H}$.: Inverse problems in hydrodynamic lubrication and design directives for lubricated flexible surfaces. Proceedings of the International Symposium on Lubrication and Wear, Houston, pp. 1-151, McCutchan Publishing Corp., Berkeley (CA), (1963)

[33] Sperka P., Krupka I., Hartl M.: Analytical Formula for the Ratio of Central to Minimum Film Thickness in a Circular EHL Contact. Lubricants 6, 80 (2018)

[34] Bair S., Liu Y., Wang, Q.J.: The pressure-viscosity coefficient for Newtonian EHL film thickness with general piezoviscous response. J. Tribol. 128, pp. 624-631 (2006)

[35] Jubault I., Molimard J., Lubrecht A.A., Mansot J.-L., Vergne P.: "In situ pressure and film thickness measurements in rolling/sliding lubricated point contacts", Tribol. Lett. 15(4), pp. 421-429 (2003) 
Appendix A - Dimensionless central and minimum film thicknesses

\begin{tabular}{|c|c|c|c|c|c|c|c|c|c|}
\hline $\mathbf{L} \backslash \mathbf{M}$ & $\mathbf{1 0}$ & $\mathbf{3 0}$ & $\mathbf{5 0}$ & $\mathbf{1 0 0}$ & $\mathbf{3 0 0}$ & $\mathbf{5 0 0}$ & $\mathbf{1 0 0 0}$ & $\mathbf{2 0 0 0}$ & $\mathbf{3 0 0 0}$ \\
\hline $\mathbf{1}$ & 2.66 & 2.43 & 2.34 & 2.20 & 1.99 & 1.88 & 1.74 & 1.60 & 1.52 \\
\hline $\mathbf{2}$ & 3.10 & 2.95 & 2.86 & 2.72 & 2.46 & 2.34 & 2.16 & 1.99 & 1.90 \\
\hline $\mathbf{3}$ & 3.54 & 3.43 & 3.34 & 3.18 & 2.88 & 2.74 & 2.54 & 2.35 & 2.24 \\
\hline $\mathbf{5}$ & 4.39 & 4.30 & 4.19 & 4.00 & 3.63 & 3.46 & 3.22 & 2.99 & 2.86 \\
\hline $\mathbf{7}$ & 5.15 & 5.06 & 4.93 & 4.72 & 4.30 & 4.11 & 3.83 & 3.56 & 3.42 \\
\hline $\mathbf{1 0}$ & 6.15 & 6.05 & 5.92 & 5.67 & 5.21 & 4.97 & 4.64 & 4.33 & 4.17 \\
\hline $\mathbf{1 5}$ & 7.56 & 7.48 & 7.33 & 7.06 & 6.52 & 6.24 & 5.85 & 5.48 & 5.27 \\
\hline $\mathbf{2 0}$ & 8.75 & 8.71 & 8.57 & 8.28 & 7.69 & 7.37 & 6.91 & 6.50 & 6.24 \\
\hline
\end{tabular}

Table A1: central dimensionless film thickness $\left(H_{c}\right)$ as a function of the dimensionless parameters $M \& L$.

\begin{tabular}{|c|c|c|c|c|c|c|c|c|c|}
\hline $\mathbf{L} \backslash \mathbf{M}$ & $\mathbf{1 0}$ & $\mathbf{3 0}$ & $\mathbf{5 0}$ & $\mathbf{1 0 0}$ & $\mathbf{3 0 0}$ & $\mathbf{5 0 0}$ & $\mathbf{1 0 0 0}$ & $\mathbf{2 0 0 0}$ & $\mathbf{3 0 0 0}$ \\
\hline $\mathbf{1}$ & 1.94 & 1.69 & 1.53 & 1.302 & 0.978 & 0.842 & 0.676 & 0.526 & 0.451 \\
\hline $\mathbf{2}$ & 2.26 & 1.96 & 1.76 & 1.483 & 1.093 & 0.942 & 0.755 & 0.589 & 0.504 \\
\hline $\mathbf{3}$ & 2.60 & 2.21 & 1.98 & 1.66 & 1.231 & 1.049 & 0.850 & 0.667 & 0.572 \\
\hline $\mathbf{5}$ & 3.20 & 2.69 & 2.41 & 2.05 & 1.51 & 1.305 & 1.064 & 0.855 & 0.737 \\
\hline $\mathbf{7}$ & 3.74 & 3.17 & 2.86 & 2.44 & 1.82 & 1.58 & 1.289 & 1.044 & 0.913 \\
\hline $\mathbf{1 0}$ & 4.51 & 3.89 & 3.54 & 3.05 & 2.31 & 2.00 & 1.63 & 1.336 & 1.184 \\
\hline $\mathbf{1 5}$ & 5.69 & 5.02 & 4.62 & 4.04 & 3.11 & 2.74 & 2.27 & 1.86 & 1.63 \\
\hline $\mathbf{2 0}$ & 6.75 & 6.07 & 5.63 & 4.98 & 3.89 & 3.41 & 2.84 & 2.33 & 2.08 \\
\hline
\end{tabular}

Table A2: minimum dimensionless film thickness $\left(H_{m}\right)$ as a function of the dimensionless parameters $M \& L$. 
Appendix B - Film thickness analytical expressions and published $h_{c} / h_{m}$ ratios

Hamrock \& Dowson [7]:

$$
\begin{gathered}
h_{c} / R_{x}=2.69 U^{0.67} G^{0.53} W^{-0.067}\left(1-0.61 e^{-0.7519}\right) \\
h_{m} / R_{x}=3.63 U^{0.68} G^{0.49} W^{-0.073}\left(1-e^{-0.7004}\right)
\end{gathered}
$$

Chittenden et al. [17]:

$$
\begin{aligned}
& h_{c} / R_{x}=4.31 U^{0.68} G^{0.49} W^{-0.073}\left(1-e^{-1.23}\right) \\
& h_{m} / R_{x}=3.68 U^{0.68} G^{0.49} W^{-0.073}\left(1-e^{-0.67}\right)
\end{aligned}
$$

Masjedi \& Khonsari [18]:

$$
\begin{aligned}
& h_{c} / R_{x}=3.672 U^{0.663} G^{0.502} W^{-0.045}\left(1-0.573 e^{-0.74}\right) \\
& h_{m} / R_{x}=1.637 U^{0.711} G^{0.650} W^{-0.09}\left(1-0.974 e^{-0.676}\right)
\end{aligned}
$$

\section{Chevalier Table [12]}

\begin{tabular}{|c|c|c|c|c|c|}
\hline $\mathbf{L} / \mathbf{M}$ & $\mathbf{1 0}$ & $\mathbf{3 0}$ & $\mathbf{1 0 0}$ & $\mathbf{3 0 0}$ & $\mathbf{1 0 0 0}$ \\
\hline $\mathbf{0}$ & 1.26 & 1.25 & 1.33 & 1.48 & 1.93 \\
\hline $\mathbf{2}$ & 1.35 & 1.48 & 1.8 & 2.23 & 3.28 \\
\hline $\mathbf{5}$ & 1.35 & 1.57 & 1.92 & 2.42 & 3.43 \\
\hline $\mathbf{1 0}$ & 1.35 & 1.54 & 1.87 & 2.33 & 3.20 \\
\hline $\mathbf{2 0}$ & 1.31 & 1.46 & 1.72 & 2.08 & 2.79 \\
\hline
\end{tabular}

Table B1: variations of the $h_{c} / h_{m}$ ratio as a function of $M$ and $L$ according to Chevalier [12].

\section{Sperka, Krupka and Hartl [33]}

\begin{tabular}{|c|c|c|c|c|c|c|c|c|}
\hline $\mathbf{L} / \mathbf{M}$ & $\mathbf{1 0}$ & $\mathbf{2 0}$ & $\mathbf{5 0}$ & $\mathbf{1 0 0}$ & $\mathbf{2 0 0}$ & $\mathbf{5 0 0}$ & $\mathbf{7 5 0}$ & $\mathbf{1 0 0 0}$ \\
\hline $\mathbf{1}$ & 1.37 & 1.39 & 1.52 & 1.67 & 1.87 & 2.20 & 2.38 & 2.50 \\
\hline $\mathbf{2}$ & 1.37 & 1.42 & 1.61 & 1.81 & 2.04 & 2.43 & 2.64 & 2.78 \\
\hline $\mathbf{5}$ & 1.36 & 1.49 & 1.71 & 1.93 & 2.18 & 2.62 & 2.85 & 2.02 \\
\hline $\mathbf{7}$ & 1.37 & 1.49 & 1.71 & 1.92 & 2.17 & 2.60 & 2.82 & 2.00 \\
\hline $\mathbf{1 0}$ & 1.36 & 1.47 & 1.67 & 1.86 & 2.10 & 2.51 & 2.73 & 2.90 \\
\hline $\mathbf{1 5}$ & 1.32 & 1.42 & 1.59 & 1.77 & 1.98 & 2.37 & 2.58 & 2.73 \\
\hline $\mathbf{2 0}$ & 1.29 & 1.38 & 1.53 & 1.69 & 1.90 & 2.25 & 2.45 & 2.61 \\
\hline
\end{tabular}

Table B2: variations of the $h_{c} / h_{m}$ ratio as a function of $M$ and $L$ according to Sperka, Krupka and Hartl [33], limited to the case where $\alpha_{\text {film }}=20.6 \mathrm{GPa}^{-1}$ and for $M \geq 10$ and $L \leq 20$. 
Analytical expression derived by Sperka et al [33]:

$$
h_{c} / h_{m}=1+0.1 \cdot \alpha_{f i l m}{ }^{0.128} \cdot M^{0.38}-\sqrt{M} \cdot\left[\left(\alpha_{f i l m}{ }^{0.2} \cdot \ln (L)-3\right) / 22.7\right]^{2}
$$

Where $\alpha_{f i l m}$ is defined in [34]:

$$
\alpha_{f i l m}=\alpha^{*}(1-\exp (-3))
$$




\section{Notations}

$a \quad$ dry or Hertzian contact radius (m)

$A_{1}, A_{2}$ parameters in the modified Yasutomi-WLF model

$b_{1}, b_{2}$ parameters in the modified Yasutomi-WLF model

$C_{1}, C_{2}$ parameters in the modified Yasutomi-WLF model

$E_{1}, E_{2}$ Young modulii of solids 1 and $2(\mathrm{~Pa})$

$E^{\prime} \quad$ reduced modulus of elasticity $(\mathrm{Pa}) 2 / E^{\prime}=\left(1-v_{1}^{2}\right) / E_{1}+\left(1-v_{2}^{2}\right) / E_{2}$

$G \quad$ dimensionless material parameter (Hamrock \& Dowson) $=\alpha^{*} . E^{\prime}$

$h_{c} \quad$ central film thickness $(\mathrm{m})$

$h_{m} \quad$ minimum film thickness $(\mathrm{m})$

$H_{c} \quad$ dimensionless central film thickness $(-)=h_{c} /\left(R_{x} \cdot U^{0.5}\right)$

$H_{m} \quad$ dimensionless minimum central film thickness $(-)=h_{m} /\left(R_{x} \cdot U^{0.5}\right)$

$K_{0}^{\prime}, K_{00}$ parameters of the Murnagham equation of state

$L \quad$ dimensionless material parameter (Moes) $=G \cdot(2 U)^{0.25}$

$\tilde{L} \quad$ natural logarithmic value of $L$

$M \quad$ dimensionless load parameter (Moes) for point contact $=W /(2 U)^{0.75}$

$\widetilde{M} \quad$ natural lobarithmic value of $M$

$p_{H} \quad$ Hertzian pressure (GPa)

$R_{x} \quad$ reduced radius of curvature $(\mathrm{m})$

$T$ temperature $\left({ }^{\circ} \mathrm{C}\right)$

$T_{g 0} \quad$ glass transition temperature at ambient pressure $\left({ }^{\circ} \mathrm{C}\right)$

$u_{e} \quad$ mean entrainment velocity $(\mathrm{m} / \mathrm{s})=\left(u_{1}+u_{2}\right) / 2$

$u_{1}, u_{2}$ velocity in the $x$-direction of surfaces 1 and $2(\mathrm{~m} / \mathrm{s})$

$U \quad$ dimensionless speed parameter (Hamrock \& Dowson) $=\mu \cdot u_{e} /\left(E^{\prime} \cdot R_{x}\right)$

$w \quad \operatorname{normal} \operatorname{load}(\mathrm{N})$

$W \quad$ dimensionless load parameter (Hamrock \& Dowson) $=w /\left(E^{\prime} \cdot R_{x}^{2}\right)$

$\alpha^{*} \quad$ reciprocal asymptotic isoviscous pressure, according to Blok [32] $\left(\mathrm{Pa}^{-1}\right)$

$\alpha_{\text {film }}$ general pressure viscosity coefficient for film forming, according to Bair [34] $\left(\mathrm{Pa}^{-1}\right)$

$\beta_{K} \quad$ parameter of the Murnagham equation of state

$v_{1}, v_{2}$ Poisson coefficient of solids 1 and 2

$\mu \quad$ lubricant dynamic viscosity (Pa s)

$\mu_{g} \quad$ dynamic viscosity at the glass transition ( $\mathrm{Pa} \mathrm{s}$ )

$\rho \quad$ lubricant density $\left(\mathrm{kg} \cdot \mathrm{m}^{-3}\right)$

$\rho_{0} \quad$ lubricant density at ambient pressure $\left(\mathrm{kg} \cdot \mathrm{m}^{-3}\right)$ 
Figures
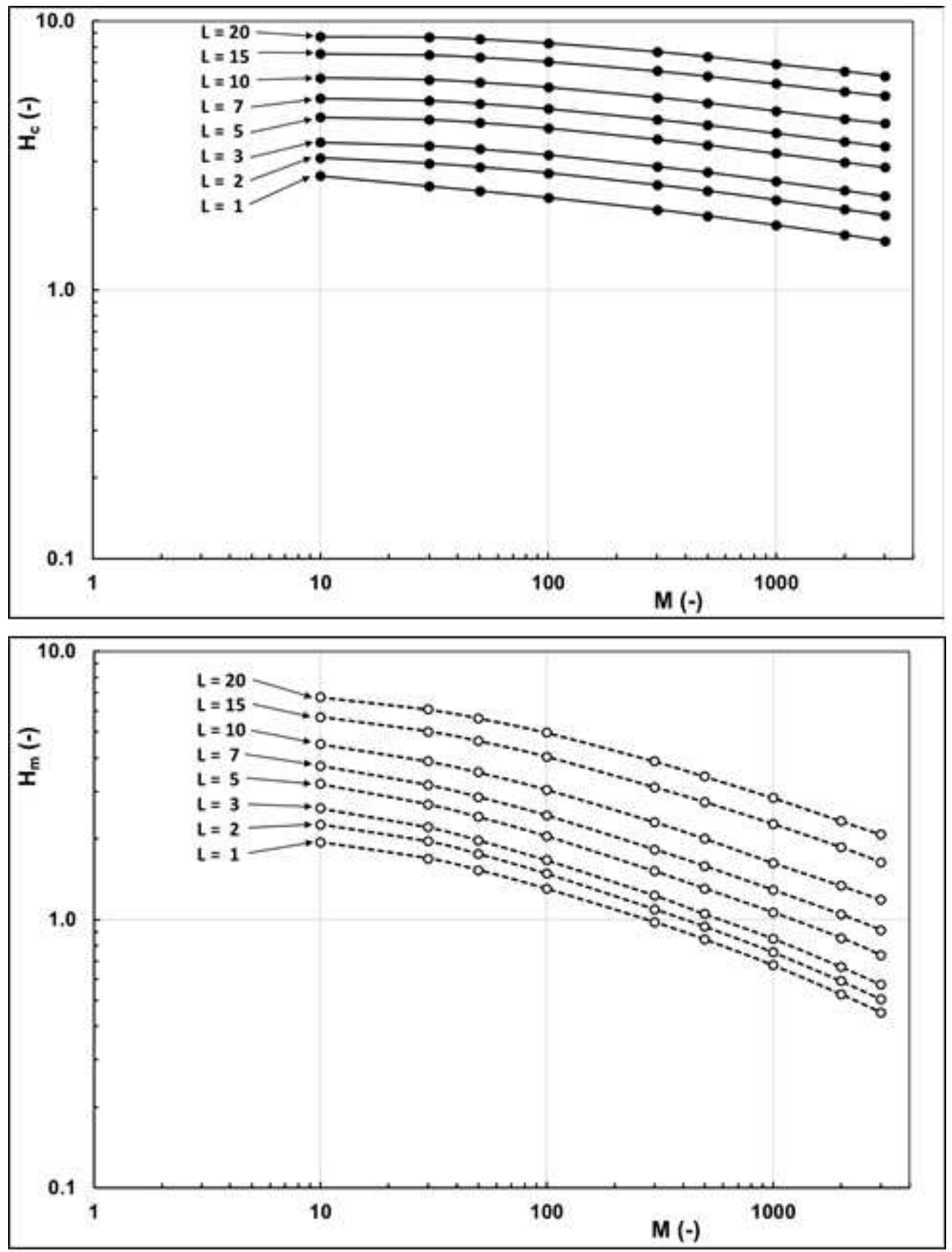

Figure 1

See the Manuscript Files section for the complete figure caption. 


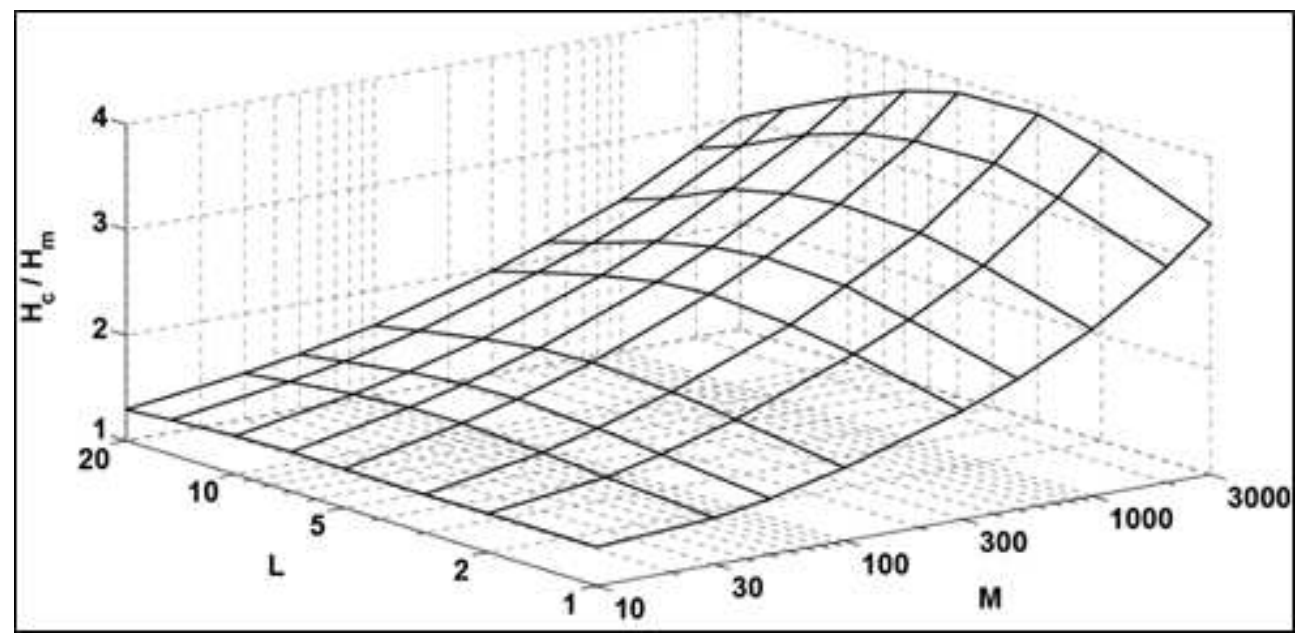

Figure 2

See the Manuscript Files section for the complete figure caption.
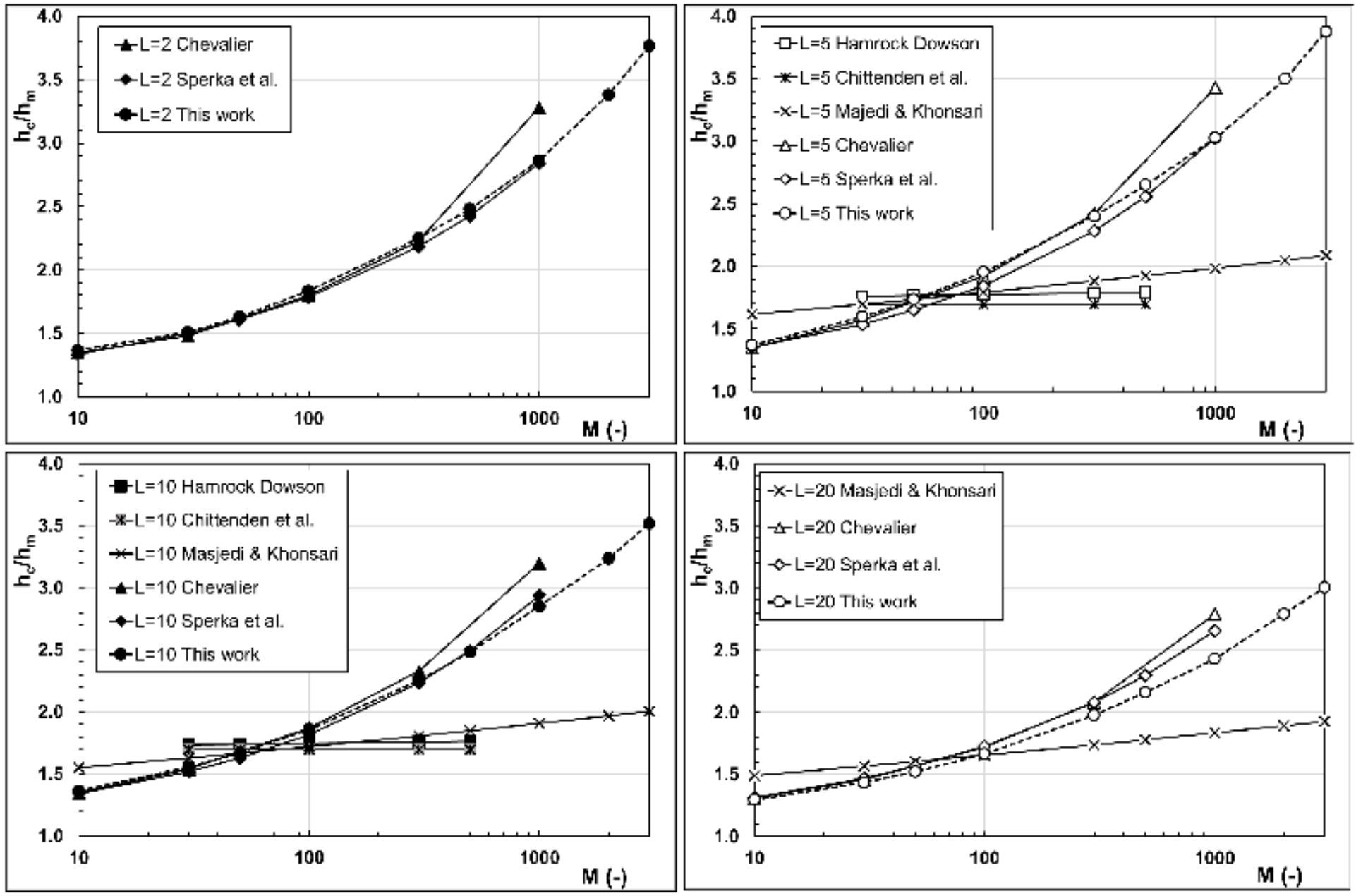

Figure 3

See the Manuscript Files section for the complete figure caption. 


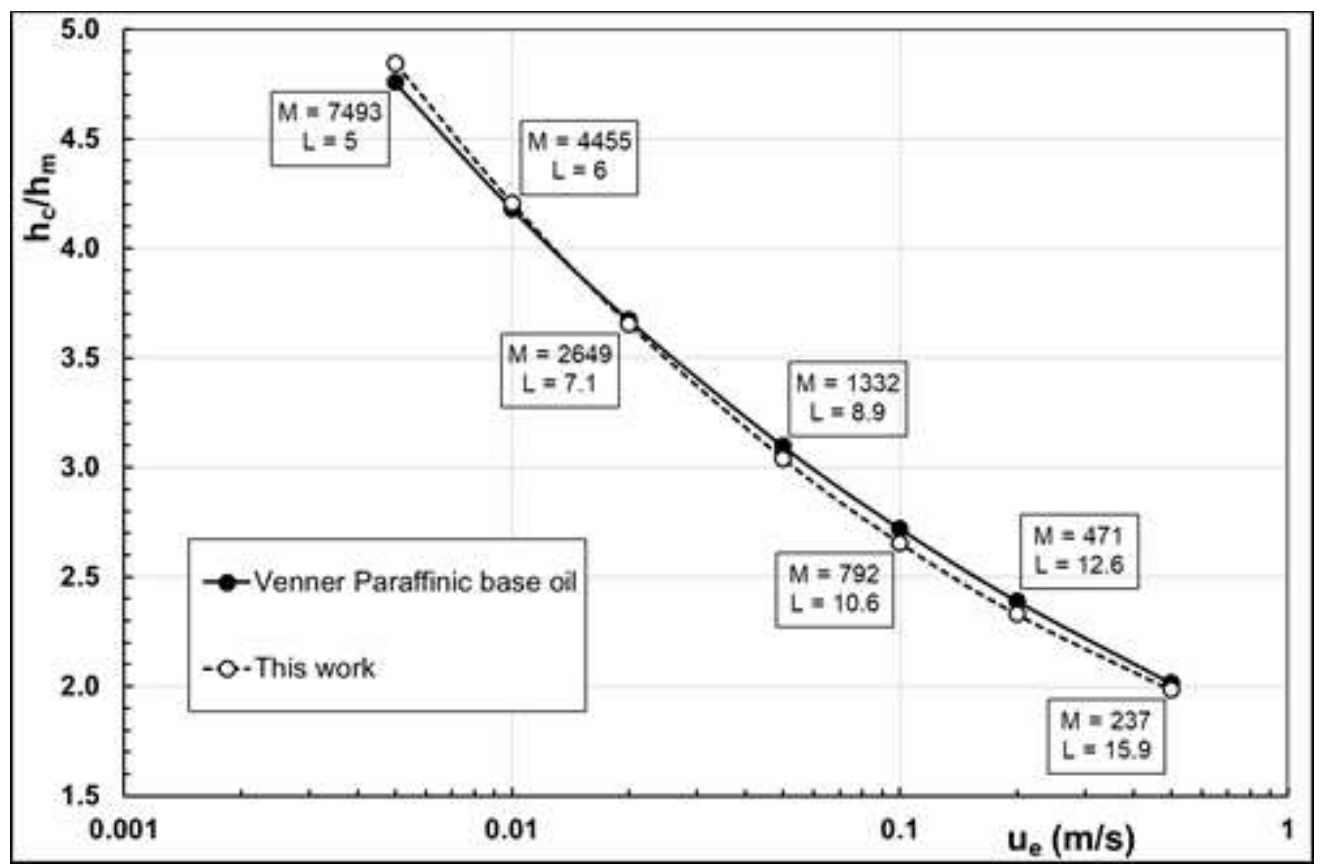

\section{Figure 4}

See the Manuscript Files section for the complete figure caption.

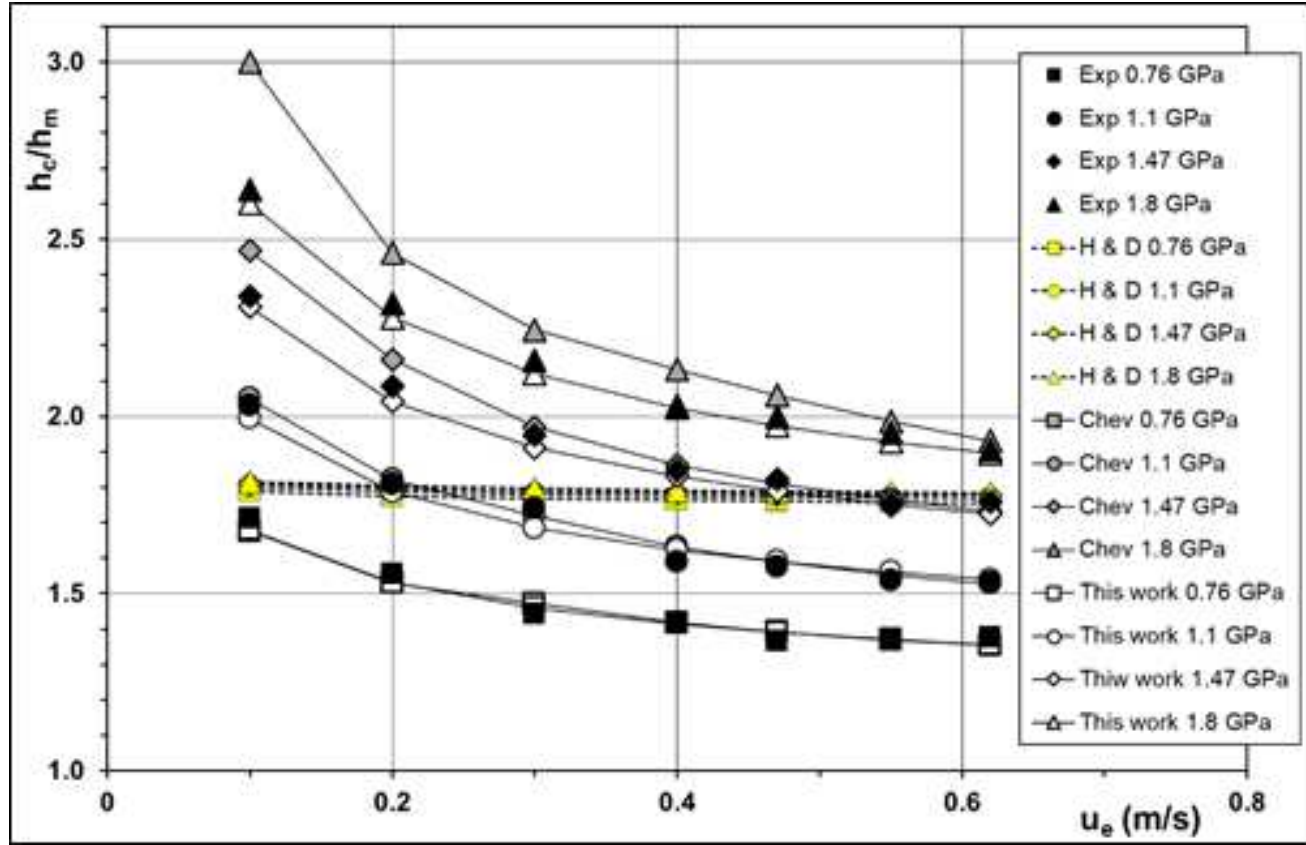

Figure 5

See the Manuscript Files section for the complete figure caption. 


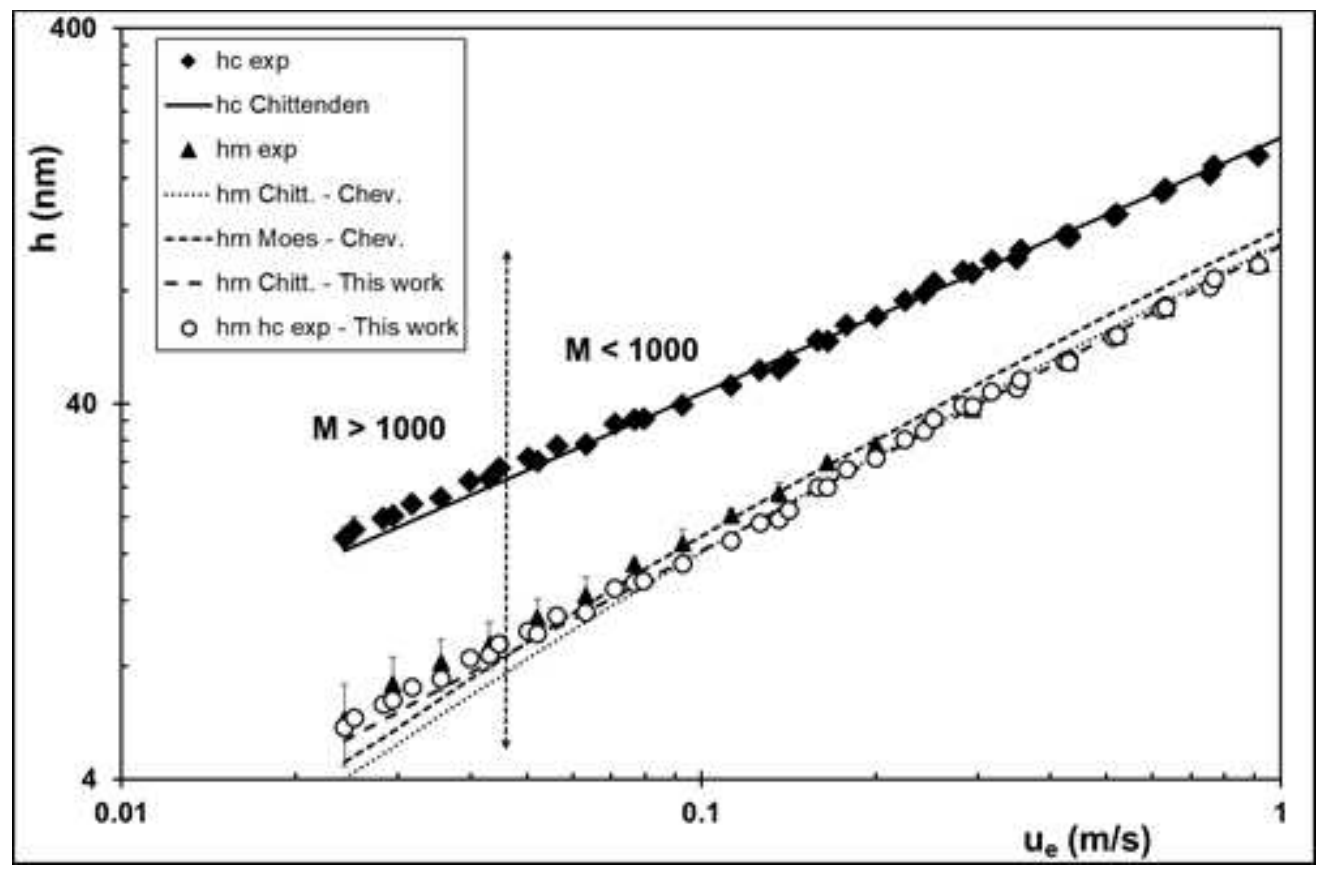

Figure 6

See the Manuscript Files section for the complete figure caption. 